\title{
REDES DISCURSIVAS: LEITURA, LIVROS E LITERATURA
}

\author{
FERNANDA CORREA SILVEIRA GALLI ${ }^{1}$
}

Universidade Estadual Paulista

Instituto de Instituto de Biociências, Letras e Ciências Exatas

R. Cristóvão Colombo, 2265, Jardim Nazareth, 15054-000 - São José do Rio Preto, SP

fcsgalli@hotmail.com

\begin{abstract}
Resumo. Com base na perspectiva teórica da Análise do Discurso pecheuxtiana, propomos neste artigo uma reflexão em torno das redes discursivas que se tecem sobre leitura, livros e literatura, a partir da hipótese de que há um atravessamento dos seus processos de constituição que faz com que as redes de sentidos (sobre leitura, livros e literatura) se entrecruzem e, nesse entrecruzamento, discursivizam o livro como um "objeto" legitimado e a literatura como uma exigência (BLANCHOT, 2005) para a prática da leitura. Para tanto, analisamos relatos escritos por professores da Educação Básica sobre o trabalho com a leitura em sala de aula. Interessa-nos, de modo particular, investigar o funcionamento das diferentes formações discursivas (FD) e das posições ideológicas que determinam o que pode e deve ser dito (PÊCHEUX, 2009) sobre a prática da leitura, bem como sua relação com os livros e com a literatura.
\end{abstract}

Palavras-chave: redes discursivas; leitura; livro; literatura.

\begin{abstract}
Based on the theoretical perspective of Pêcheux's Discourse Analysis, we propose in this article a reflection on the discursive networks that are weaving on reading, books and literature, from the hypothesis that there is a crossing of yours processes of constitution that causes that the networks of meanings (about reading, books and literature) intersect, and in this intertwining, they discursive the book as a legitimized "object" and literature as a requirement (BLANCHOT, 2005) for the practice of reading. Therefore, we analyzed reports written by teachers of Basic Education about working with reading in the classroom. What interests us, particularly, to investigate the functioning of the different discursive formations and the ideological positions that determine what can and should be said (PECCHEUX, 2009) about the practice of reading, as well as its relationship with books and with the literature.
\end{abstract}

Keywords: discourse networks; reading; book; literature.

\footnotetext{
${ }^{1}$ Doutora em Linguística Aplicada pelo IEL/UNICAMP. Docente e pesquisadora vinculada ao Programa de Pós-graduação em Estudos Linguísticos do IBILCE/UNESP. Bolsista do PNPD/CAPES.
} 
O Livro: o que significava essa palavra para Mallarmé? A partir de 1866, ele sempre pensou e disse a mesma coisa.

Entretanto, o mesmo não é sempre o mesmo.

Uma das tarefas seria a de mostrar por que e como essa repetição constitui o movimento que abre, lentamente, um caminho.

(BLANCHOT, 2005, p. 327)

\section{CONSIDERAÇÕES INICIAIS}

Os resultados das últimas edições da pesquisa "Retratos da Leitura no Brasil" (RLB), realizada pelo Instituto Pró-Livro $(2012,2016)$, dão destaque ao estudo sobre a leitura de livros, inclusive os digitais, e apontam sua crescente importância no cenário leitor brasileiro. Considerada uma referência nacional no que diz respeito à avaliação do comportamento leitor no Brasil, as edições ${ }^{2}$ da pesquisa RLB, realizadas por meio de entrevistas com a população brasileira com cinco anos de idade ou mais - alfabetizados ou não -, destacam que leitor é aquele que leu ao menos um livro, inteiro ou em partes, nos últimos três meses que antecedem a pesquisa. Com a divulgação dos resultados, o interesse da "Retratos da Leitura no Brasil" é mapear, por meio de tabelas e gráficos comparativos, "o comportamento leitor segundo a percepção da leitura no imaginário coletivo; o perfil do leitor e do não leitor de livros; as preferências e motivações dos leitores; as influências e os canais e formas de acesso ao livro" (PRÓ-LIVRO, 2012, p.9). Também faz parte dos objetivos da pesquisa RLB, apresentar resultados que possam: i) conferir se estamos lendo mais; ii) conhecer a percepção da população sobre o livro; iii) medir uma eventual evolução em torno das práticas leitoras, do acesso aos livros. Esses dados apontam, para o que nos interessa discutir, uma estreita relação do "objeto" livro, mais especificamente os literários, com a prática de leitura.

A pesquisa "Retratos da Leitura no Brasil" discursiviza o livro como um "objeto" legitimado para leitura, ${ }^{3}$ de modo que os discursos sobre leitura e literatura parecem se relacionar, se entrecruzar e/ou, muitas vezes, se confundir, especialmente quando se pensa nas relações entre o que se pode e se deve ensinar e/ou aprender (não apenas) dentro das escolas sobre a leitura. Esses discursos, também presentes em documentos oficiais de ordem - como os que lançam diretrizes, parâmetros e orientações, especialmente para o Ensino Básico - tendem a afetar sujeitos e reforçar, por meio da reprodução, o imaginário construído socialmente a respeito dos discursos sobre leitura, livros e literatura. Desse modo, trata-se de um cenário que parece ilustrar algumas controvérsias não apenas sobre as concepções - de leitura, livro e literatura, mas particularmente sobre os equívocos, como, por exemplo, o de se considerar somente livros literários, em geral os clássicos, como autorizados e legitimados para leitura, excluindo outras tantas possíveis.

\footnotetext{
${ }^{2}$ Foi lançada em 2001 e é promovida a cada três anos, com apoio da Câmara Brasileira da Indústria do Livro (CBL), do Sindicato Nacional das Editorias de Livros (SNEL), da Associação Brasileira de Editores de Livros (ABRELIVROS) e do Instituto Pró-livro (IPL). Seus resultados são "amplamente divulgados e orientaram estudos; projetos e a implantação de políticas públicas do livro e leitura no país" (PRÓ-LIVRO, 2012, p. 17).

${ }^{3} \mathrm{O}$ que também é recorrente em pesquisas que têm circulado na mídia, tais como as disponíveis em: http://g1.globo.com/jornal-da-globo/noticia/2015/04/70-dos-brasileiros-nao-leram-em-2014-diz-pesquisada-fecomercio-rj.html; http://jconline.ne10.uol.com.br/canal/cultura/literatura/ noticia/2015/04/08/quedano-habito-de-leitura-revela-dificuldade-de-formar-leitores-no-brasil-175698.php; http://zh.clicrbs.com.br/rs/entretenimento/noticia/2015/04/por-que-os-brasileiros-leem-tao-pouco-47351 12.html\#; http://www.premiorbsdeeducacao.com.br/2015/2014/08/17/vamos-aumentar-os-indices-deleitura-do-brasil-22/. Acesso em 05 abr. 2018.
} 
Com base no aporte teórico da Análise do Discurso de linha francesa pecheuxtiana, propomos uma reflexão em torno das redes discursivas que se tecem sobre leitura, livros e literatura, a partir da hipótese de que há um atravessamento dos seus processos de constituição que faz com que as redes de sentidos (sobre leitura, livros e literatura) se entrecruzem e, nesse entrecruzamento, discursivizam o livro como um "objeto" legitimado e a literatura como uma exigência (BLANCHOT, 2005) para a prática da leitura. Para tanto, analisamos relatos escritos por professores da Educação Básica sobre o trabalho com a leitura em sala de aula. Interessa-nos, particularmente, investigar o funcionamento das diferentes formações discursivas (FD) e das posições ideológicas que determinam o que pode e deve ser dito (PÊCHEUX, 2009) sobre a prática da leitura, bem como sua relação com os livros e com a literatura. $\mathrm{O}$ texto está dividido em duas partes, além da introdutória e da conclusiva: na primeira parte, apresentamos considerações sobre a teoria discursiva, mais especificamente a perspectiva pecheuxtiana e alguns conceitos fundantes - como discurso, sujeito, ideologia, formação discursiva; na segunda parte, analisamos três relatos - sobre o trabalho com a leitura - produzidos por professores em exercício na Educação Básica de uma Cooperativa de Ensino, no interior do Estado de São Paulo.

\section{QUESTÕES TEÓRICAS}

Em seu primeiro escrito ${ }^{4}$ que circula na academia, Pêcheux apresenta um questionamento sobre o modo como as Ciências Sociais silenciam as relações de desigualdade que permeiam as condições de produção e deixam de lado as questões de fronteira. Pêcheux busca deslocar as Ciências Sociais do positivismo e passa a inscrevêlas na esfera do humanismo que, sob as bases marxistas, as "questões sobre subjetividade, ideologia, confrontos e lutas de classe ocupam lugares essenciais", conforme aponta Zandwais (2009, p.14-15). Nesse primeiro momento, Pêcheux apresenta um tratamento compartimentado das práticas (técnica, política, científica, etc.), sobretudo as ideológicas, como se elas não fossem constitutivas das demais. A concepção de ideologia (idealista, de influência hegeliana) a que ele se filiava, na época, abrangia uma oposição do conceito em relação à ordem do real, do impossível. Pensar a ideologia desse modo, seria pensála fora da história e da ideia de ciência positivista que Pêcheux buscava contestar.

Em "Observações para uma Teoria Geral das Ideologias"5, Pêcheux (1967) propõe, pois: i) investigar os efeitos do conhecimento científico; ii) construir uma ciência das formações sociais (materialismo histórico e materialismo dialético); e iii) reportar a ideologia à leitura do modo de produção das relações sociais (ZANDWAIS, 2009, p. 18). No mesmo artigo, ele traz uma abordagem preliminar sobre a relação do sujeito com a ideologia e com o sentido. É em 1969 que o filósofo se aproxima ainda mais de Althusser e começa a dar forma à Análise do Discurso como disciplina de autonomia em relação à Linguística, o que é formalizado em Análise Automática do Discurso (AAD-69), obra que traz uma releitura da concepção de estrutura encontrada em Saussure. Pêcheux busca mostrar que "língua e discurso têm materialidades distintas e, ao mesmo tempo, intercomplementares", de maneira que, "enquanto a base linguística seria tomada como a materialidade necessária para a realização da ideologia, os processos discursivos remeteriam para os lugares nos quais as ideologias funcionam e produzem determinados

\footnotetext{
${ }^{4}$ Intitulado "Reflexões sobre a Situação Teórica das Ciências Sociais e especialmente da Psicologia Social", publicado em Les Cahiers pour l'Analyse (Ecole Normale Supérieure), em 1966, sob o pseudônimo de Thomas Herbert.

${ }^{5}$ Publicado, originalmente, em Les Cahiers pour l'Analyse, n. 9, em 1967.
} 
efeitos de sentidos a partir de seus modos de inscrição em determinadas ordens históricosimbólicas" (ZANDWAIS, 2009, p. 22). Esse funcionamento se dá por meio das condições de produção, as quais criam formas de inscrição da "história na ordem do discurso" e o do "discurso no campo da práxis", contribuindo, sobremaneira, para o esboço da então denominada Análise do Discurso - "uma disciplina antipositivista e antiformalista de linguagem" (ZANDWAIS, 2009, p. 23).

Com a articulação de três regiões do conhecimento (marxismo, linguística e psicanálise), Pêcheux começa a traçar as bases de uma disciplina alicerçada no materialismo histórico ("teoria das formações sociais e de suas transformações") das Ciências Humanas e, como parte desse processo de desconstrução, passa a estabelecer relações entre ideologia, discurso e subjetividade, tratando, assim, "do modo como a ideologia 'apreende' o sujeito e se corporifica na materialidade discursiva" (ZANDWAIS, 2009, p. 25). O lugar do discurso - enquanto objeto teórico e enquanto objeto empírico - torna-se mais visível, e a história, nesse caso, é recolocada como nãolinear, heterogênea e não-contínua. A partir dessas questões, as relações do sujeito com a história e, ainda, com os sentidos não podem ser mais concebidas do ponto de vista das "representações subjetivas que os sujeitos constroem sobre o real, mas, ao contrário, é o campo da prática concreta, da experiência, do vivido, que determina como o real precisa ser representado e significado como discurso", destaca Zandwais (2009, p. 27).

Nessa esteira de reflexões a respeito da(s) materialidade(s) da ideologia, Pêcheux introduz o conceito de formação discursiva (FD) para pensar não só materialidades em termos de práticas, mas também materialidades discursivas, conferindo ao discurso um aspecto material da ideologia e inaugurando uma questão jamais pensada: a da relação entre signo e ideologia como constitutiva do sentido. ${ }^{6}$ Ao apontar que as formações discursivas dependem das condições de produção, Pêcheux "insere o objeto discursivo, isto é, a materialidade significante do discurso, na materialidade histórica, de tal modo que é pelo viés da inscrição do discurso em uma ordem ao mesmo tempo simbólica e histórica que a linguagem carrega os 'pesos' das diferentes ideologias em seu interior" (ZANDWAIS, 2009, p. 29). Desse modo, Pêcheux apresenta um deslocamento da definição de FD cunhada por Foucault: para este, "o sujeito é uma posição que pode ser ocupada por qualquer indivíduo, de modo alternado, em uma série de enunciados produzidos em diferentes momentos"; para aquele, se "o sujeito é 'capturado' pelas determinações históricas que 'o falam' antes que ele fale de si mesmo, torna-se necessário convir que os lugares de sujeito a serem 'ocupados' por determinados indivíduos ao invés de outros [...] não podem ser pensados como lugares de "câmbio acessível"” (ZANDWAIS, 2009, p. 30-31). Da visão pecheuxtiana, portanto, a FD está intimamente ligada à formação ideológica, às condições de produção e, também, "a um determinado tipo de subjetividade tomada da/na história” (ZANDWAIS, 2009, p. 30).

Feitas essas considerações teóricas de base, procuramos, a seguir, no percurso de análise do material, refletir sobre como as diferentes formações discursivas (FD) se relacionam a posições ideológicas que determinam e/ou limitam o que pode e deve ser dito (PÊCHEUX, 2009), na ordem do discursivo, a respeito da leitura, do livro e da literatura.

\footnotetext{
${ }^{6}$ Com isso, Pêcheux aprofunda, portanto, "uma questão fundamental - a da linguagem - que não teria sido senão superficialmente pensada por Marx ou Althusser, mas já pensada por Volochinov/Bakhtin em 1929” (ZANDWAIS, 2009, p. 28).
} 


\section{LEITURA, LIVROS E LITERATURA: EFEITOS DE SENTIDO EM DISCURSO}

No texto "Sobre os contextos epistemológicos da análise do discurso", publicado em 1984 e traduzido para o português em 1999, Pêcheux traz uma abordagem sobre a epistemologia da Análise do Discurso e propõe o encontro transdisciplinar, conforme já acenado, entre a Linguística, as Ciências Sociais e a Psicologia (depois, a Psicanálise). Mesmo permeado por confrontos e divisões, esse encontro transdisciplinar tornou-se a base para se pensar a respeito da des-construção de "uma aproximação discursiva dos processos ideológicos" por meio "dos funcionamentos e dis-funcionamentos institucionais, de debates e de confrontos de toda ordem" (PÊCHEUX, 1999, p. 7). A partir dos sistemas de pensamentos ou das ideologias, há uma abertura que permite "trabalhar sobre os textos de outra maneira, colocando em causa a transparência da língua. Juntar e interpretar séries textuais em que se inscrevem discursivamente" - nesta abordagem, sobre leitura, livro e literatura - significa "abandonar as certezas associadas ao enunciado documental” (PÊCHEUX, 1999, p. 8).

Interessa-nos, pois, tomar os relatos produzidos pelos professores - "enunciado documental" ou documento - como um monumento, tal como proposto por Pêcheux a partir (da releitura) da arqueologia foucaultiana, o que nos permite compreendê-lo como "um vestígio discursivo em uma história, um nó singular em uma rede" (PÊCHEUX, 1999, p. 9). Tomando o documento como uma discursividade que se constitui na história, Pêcheux assevera que é preciso levar em conta que o interdiscurso - conjunto das formações discursivas que se inscreve no nível da constituição do discurso, e que "trabalha com a resignificação do sujeito sobre o que já foi dito, o repetível" (FERREIRA, 2001, p.15) - funciona "como um dos pontos cruciais desse empreendimento, conduzindo a análise de discurso a se distanciar ainda mais de uma concepção classificatória que dava aos discursos escritos oficiais 'legitimados' um privilégio que se mostra cada vez mais contestável" (PÊCHEUX, 1999, p. 9). Essas questões são extremamente importantes para a reflexão que aqui propomos sobre as redes discursivas, na medida em possibilita a problematização sobre os deslocamentos do sujeito entre formações discursivas (FD).

Destacamos que a concepção de sujeito do discurso, assumida a partir da teoria discursiva pecheuxtiana, pressupõe que, ao se inscrever em um determinado lugar discursivo, o sujeito se relaciona tanto com a forma-sujeito histórica, quanto com a posição-sujeito. Desse modo, a relação daquele que enuncia se dá nos deslocamentos, nos movimentos de identificação e/ou desidentificação com o lugar discursivo: mais especificamente, no nível do interdiscurso, com o sujeito-histórico, e no nível do intradiscurso, ${ }^{7}$ com a posição-sujeito. Nesse deslocamento, do lugar empírico para o discursivo, o sujeito é afetado pelo inconsciente e tem a ilusão de uma possibilidade de apagamento do seu lugar social, o que funciona apenas como efeito, dado que toda inscrição envolve, sempre, uma determinação ideológica.

Do conjunto ${ }^{8}$ do material produzido por professores em exercício na Educação Básica de uma Cooperativa de Ensino no interior do Estado de São Paulo, em uma das

\footnotetext{
7 “'Simulacro material do interdiscurso, na medida em que fornece-impõe a 'realidade' ao sujeito, matériaprima na qual o indivíduo se constitui como sujeito falante numa determinada formação discursiva que o assujeita" (FERREIRA, 2001, p. 16).

${ }^{8} \mathrm{O}$ material coletado integra o banco de dados do projeto de pesquisa de pós-doutorado intitulado "Redes de leitura, redes de (in)formação", financiado pelo PNPD/CAPES e desenvolvido, desde 2014, no âmbito das atividades do Programa de Pós-graduação em Estudos Linguísticos, na linha de pesquisa "Oralidade e
} 
atividades da intitulada "Oficina de leitura: formação de professores em HTPC", selecionamos três relatos para investigar o funcionamento das diferentes formações discursivas (FD) e das posições ideológicas que determinam o que pode e deve ser dito sobre a prática da leitura, e sua relação com os livros e com a literatura, conforme já sinalizado. A referida oficina foi realizada no primeiro semestre de 2015 , precisamente no mês de abril, no espaço físico da Cooperativa de Ensino, em horário de HTPC (Horário De Trabalho Pedagógico Coletivo). A proposta consistia em: (i) compreender a noção de leitura; (ii) refletir sobre a prática da leitora; e (iii) abordar o papel do professor (leitorformador) na formação de leitores. Após a discussão sobre a memória histórica e os discursos sociais a respeito da leitura, algumas questões nortearam as reflexões com os professores, dentre elas: O que é leitura?; Qual a noção de leitura abordada na escola?; Por que é "preciso" ler?; O que é ler na era da conexão?; Como abordar a importância da leitura para a (trans)formação social do sujeito/aluno/professor?; etc.

Esse contexto historicossocial e de enunciação dos sujeitos-professores constitui parte dos sentidos dos discursos por eles produzidos e materializados nos relatos escritos, os quais se apresentam não como um conjunto de enunciados uno, homogêneo e não conflitante, mas como dizeres divergentes, marcados por uma heterogeneidade constitutiva e por posições ideológicas, algumas vezes, conflitantes. Sobre esse aspecto, sinalizamos que, em uma formação ideológica, as relações de força nem sempre estão em conflito, já que elas podem emergir como relações de aliança e, ainda, de dominação. É, portanto, uma formação ideológica (FI) que rege uma formação discursiva (FD), como veremos nos relatos que os sujeitos-professores da Educação Básica produziram a respeito do trabalho com a leitura em sala de aula - mais especificamente, a partir do enunciado: Na sua opinião, como o trabalho de leitura pode ser desenvolvido na sala de aula? Dê exemplo(s). O interesse pela compreensão dos processos de produção de sentidos sobre as/por meio das práticas da leitura na esfera acadêmica e escolar faz parte dos objetivos de nossa pesquisa de pós-doutorado ${ }^{9} \mathrm{em}$ andamento. Vejamos o primeiro relato, reproduzido a seguir (Figura 1).

Nesse relato (Figura 1) ${ }^{10}$, o sujeito-professor discursiviza o encaminhamento das atividades com a leitura em sala de aula e, para tanto, recorta elementos naturalizados pelo senso comum da prática leitora (leitor, livro, interpretação). Essa prática da leitura é compreendida a partir de outros elementos (capa, tamanho, ilustrações, assunto) que, embora textualizados, numa linearidade parecem representar mais a concretude do livro do que aquilo que estaria relacionado a uma interpretação, aos "pontos de deriva possíveis" (PÊCHEUX, 2009); por outro lado, vemos emergir um (imaginário sobre) outro modo de leitura que elege outra forma de relação do leitor com o texto, tal como discute Orlandi (2000, p.10). Interpretar, sob a ótica discursiva, é produzir sentidos, a

letramento", da Universidade Estadual Paulista “Júlio de Mesquita Filho" (campus de São José do Rio Preto). O objetivo geral da pesquisa é investigar os processos de produção de sentidos que se dão em/por práticas da leitura e refletir sobre seu funcionamento informativo-enunciativo-discursivo na produção do conhecimento, tanto na formação de universitários e pós-graduandos como futuros professores, quanto na formação de professores em exercício. Para tanto, propomos um diálogo entre as teorias da Análise do Discurso (AD) de linha francesa e dos Novos Estudos de Letramento (NEL), bem como pressupostos da Ciência da Informação (CI), na tentativa de contribuir para uma discussão sobre a inscrição do sujeito-leitor nas redes de leituras e nas redes de (in)formação contemporâneas, de maneira a inscrever, também, uma reflexão acerca do político, para pensar (politicamente) a leitura, a escrita, a (in)formação, o sujeito e os sentidos.

${ }^{9}$ Conforme descrição na nota anterior.

${ }^{10}$ A codificação refere-se a: número da atividade desenvolvida (A2); número aleatoriamente atribuído ao participante da pesquisa (nesse caso, 1). 
partir de uma dada posição-sujeito, o que pode se distanciar do caráter individual (da interpretação) que emerge no relato - se o significante for compreendido empiricamente, ou se aproximar - se o individual permitir a manifestação da ideologia, da compreensão discursiva do sujeito.

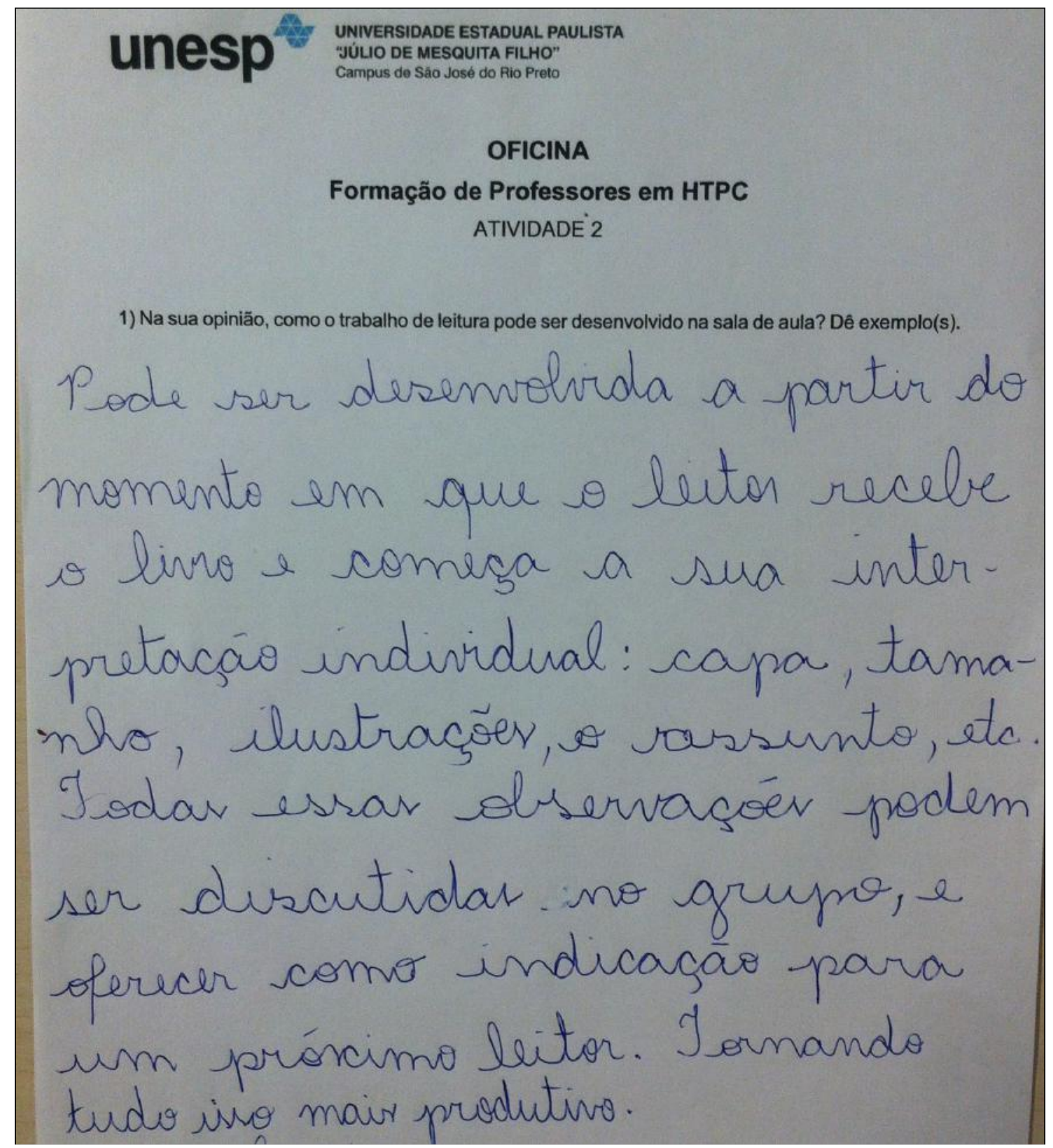

Figura 1. Relato A2_1.

Considerando a circularidade do discurso pedagógico e seu caráter informacional (ORLANDI, 1996, p.29), parece não ser possível conceber o leitor como sujeito, como posição, como "um ser social complexo e polifônico, no sentido bakhtiniano de que há outras vozes que nele falam, e que partilha, com outros sujeitos, de um imaginário social que, de certa forma, molda suas crenças, valores, pensamentos e gostos" (GRIGOLETTO, 2002, p. 106). O caráter individual parece, também, ter relação com a natureza consumista-informacional do livro, na medida em que as características concretas 
(observações como: capa, tamanho, ilustrações, assunto) são apontadas pelo sujeitoprofessor como responsáveis por suscitar o interesse (funcionar como indicação para) de outros leitores pelo livro. Ao enunciar esse modo de leitura, de reconhecimento dos elementos formais do livro, o sujeito-professor reproduz discursos que circulam socialmente e que funcionam como manifestação de certa formação ideológica - de modo particular, na esfera educacional, o trabalho com a "ficha de leitura" é muito recorrente $\mathrm{e}$, inclusive, foi discursivizado pelos professores durante as discussões.

Esses dizeres que mesclam elementos tanto de natureza consumista-informacional quanto de natureza pedagógica remetem à aderência do sujeito-professor aos discursos que também circulam ao longo da história: a ideia de livro como "objeto material" ou "coisa física", e a ideia de literatura clássica como exigência. Nessa perspectiva, o livro, que poderia ser tomado como a "soma infinita de seus possíveis", conforme a proposta de Blanchot (2005), em especial no âmbito escolar, parece emergir, no relato em questão, como um "objeto" - com edição, formato e tema diferentes - que pode ser oferecido e indicado por alguém (nesse caso, o professor e a instituição escola); e a literatura, por sua vez, se manifesta como um instrumento de/para formação, a que deve privilegiar a forma dos livros em detrimento do conteúdo e seus desdobramentos. Nessa esteira de reflexão, o conteúdo funciona como forma e essa, por sua vez, funciona como resposta ao conteúdo, de maneira que a "objetividade do sistema" e "a transmissão de informação e fixação" objetivos do discurso pedagógico (ORLANDI, 1996, p. 19) - são reproduzidas.

O livro considerado somente como "objeto" perde a sua natureza mediadora, fazendo com que os elementos importantes do processo de ensino e aprendizagem também se percam: o que interessa "não é saber utilizar o material" para algo, mas "saber o material", sua forma (capa, tamanho, ilustrações, assunto), o como o objeto "se dá em si mesmo", tal como discute Orlandi (1996, p. 21-22) ao abordar a circularidade do discurso pedagógico. A leitura, desse modo, não se resume ao domínio da forma material, do produto e/ou objeto livro somente; trata-se de um processo, o qual também não se dá somente na educação formal, já que envolve a "relação entre o leitor e o conhecimento, assim como sua reflexão sobre o mundo" (ORLANDI, 1996, p. 210). No entanto, a leitura emerge, no relato analisado (Figura 1), como uma prática marcada pelo que pode e deve ser dito, ou seja:

a leitura não emerge enquanto uma relação possível entre sujeito e história, um processo a ser instaurado pelo funcionamento ideológico de produção dos sentidos. O sentido é entendido como presente no próprio texto e o leitor é aquele sujeito capaz de "buscar as informações", isto é, aquele que apreende o sentido que supostamente estaria arraigado às palavras, [na forma], numa visão mecanicista da linguagem. (GALLI e GARCIA, 2015, p. 122)

No segundo relato (Figura 2), o sujeito-professor também privilegia o livro, ao discursivizar o trabalho com a leitura em sala de aula. Vejamos.

A compreensão do sentido de leitura é discursivizada pelo sujeito-professor do segundo relato (Figura 2) como aquela que diz respeito ao literário, ao livro dividido em capítulos, ou seja, há a inscrição de sentidos que se filiam aos discursos que circulam socialmente - como ler é ter acesso à determinado livro e/ou leitura é sinônimo de livro, os quais são sustentados, por exemplo, por pesquisas como a já citada "Retratos da Leitura no Brasil". Emerge, portanto, o caráter instrumental não apenas da prática da leitura, mas especialmente do livro, dividido em capítulos, o que também parece funcionar como 
metodologia de trabalho que aponta para uma sequência a ser seguida (pelo reconto). No entanto, é possível observar que, ao mencionar que a criança pode contar com suas próprias palavras o livro lido, o sujeito-professor expressa um efeito de contradição: de um lado, há controle, o qual se manifesta pelos passos a serem seguidos (ler capítulos e recontar o lido) para, provavelmente, cumprir um objetivo; de outro lado, há dispersão, a qual emerge pela liberdade possibilitada à criança (contar com as próprias palavras), $\mathrm{o}$ que parece contemplar a ideia da produção de sentidos da leitura. A referência à obra cinematográfica, como outra possibilidade para se trabalhar a leitura, abre brechas, também, para a emergência do efeito de liberdade que pode ser proporcionado ao leitor (à criança, nesse caso).

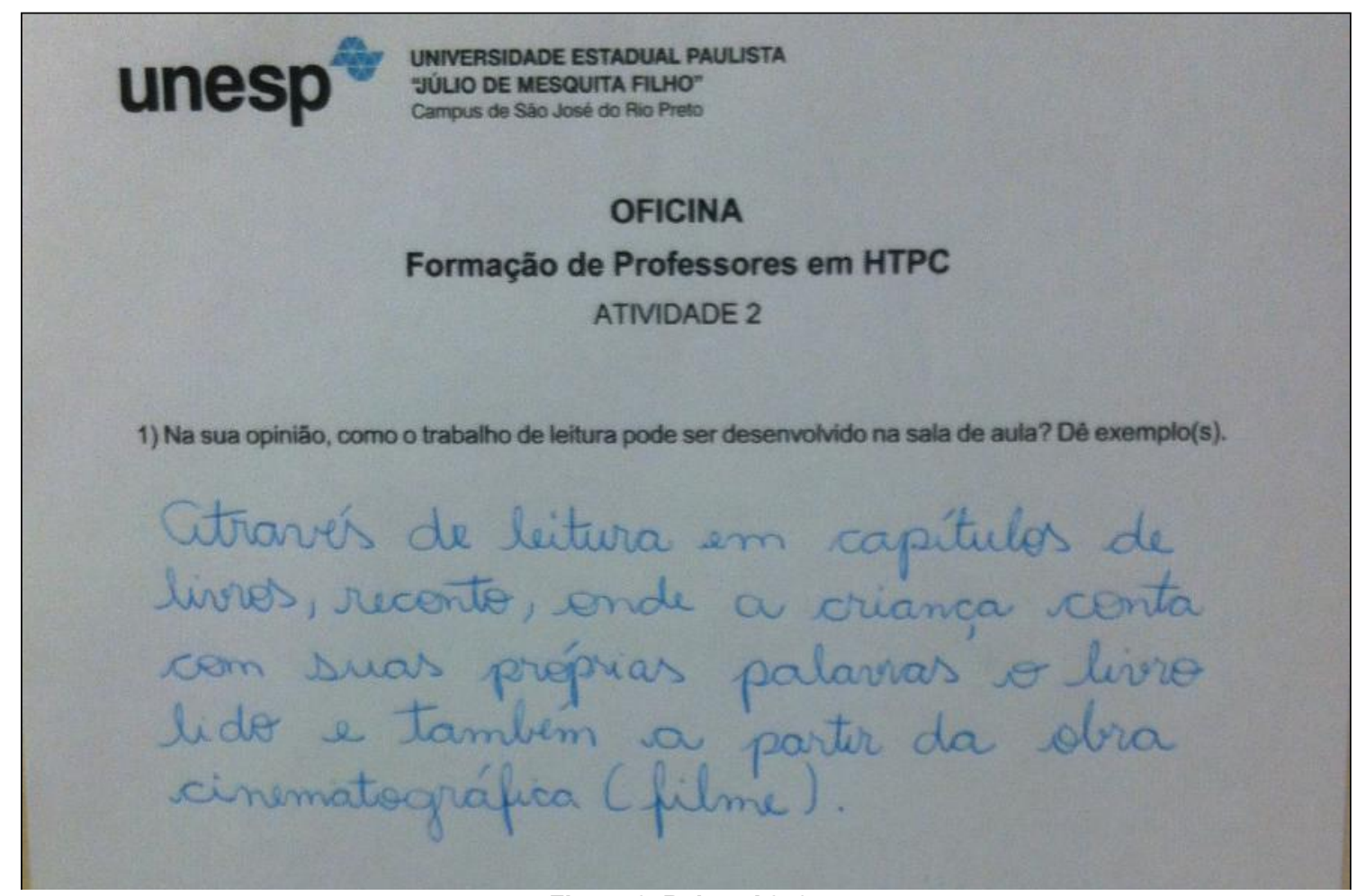

Figura 2. Relato A2_2.

Temos, ainda, nesse encaminhamento do trabalho com a leitura, um outro funcionamento que evoca práticas menos naturalizadas na esfera educacional: a adaptação da obra (filme) - entendida, no segundo relato, como sinônimo de livro pressupõe não só um deslocamento de gênero e de linguagem, mas também, e especialmente, dos modos de ler e das formas de apresentação textual, o que demanda outras orientações pedagógicas, outra metodologia. Essa inscrição do gênero obra cinematográfica no relato da Figura 2 tem relação com as atuais condições de produção, ${ }^{11}$ as quais, nesse caso, envolvem a emergência de novas textualidades relacionadas às tecnologias digitais de informação e comunicação (como outras propostas de produção de conhecimento) e a assunção do trabalho com a diversidade de gêneros ${ }^{12}$ em sala de

11 "As condições de produção fazem parte da exterioridade linguística e podem ser agrupadas em condições de produção em sentido estrito (circunstâncias de enunciação) e em sentido amplo (contexto sóciohistórico-ideológico), segundo preconiza Orlandi (1999)" (FERREIRA, 2001, p. 11).

${ }^{12}$ Em Gêneros na prática pedagógica: diálogos entre escolas e universidades (SILVA, W.R.; LIMA, P.S.; MOREIRA, T.M., 2016), os autores abordam não só os processos de ensino-aprendizagem dos gêneros, 
aula (como objeto de ensino da leitura e da escrita para as diferentes situações de interação social). Essas questões também permeiam documentos oficiais como a Base Nacional Comum Curricular (BNCC), cujo caráter normativo é reproduzido e faz com que o sujeito-professor, de seu posicionamento institucional, partilhe determinada formação discursiva e ideológica.

Vejamos, por último, o terceiro relato, reproduzido na Figura 3, a seguir.

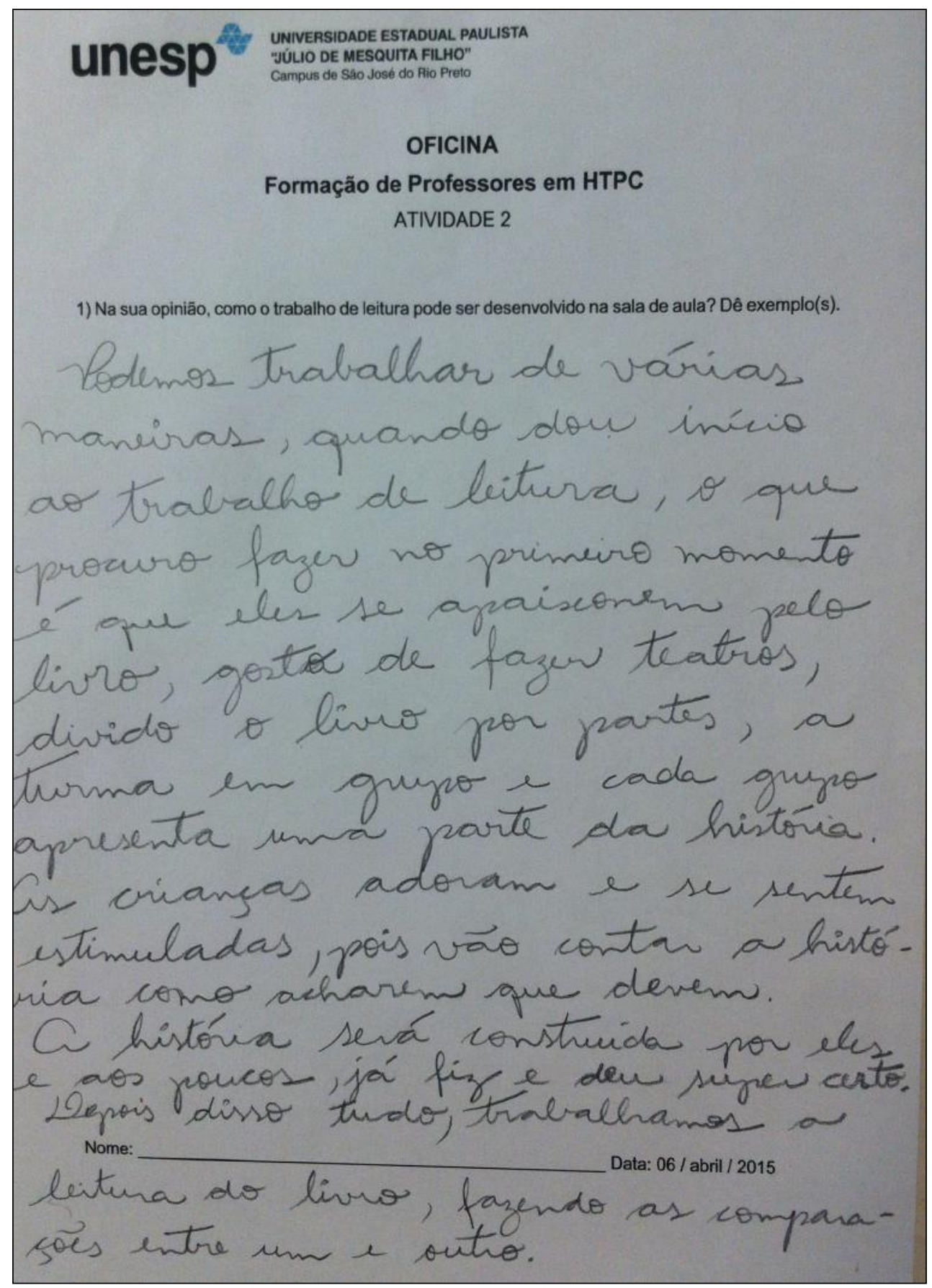

Figura 3. Relato A2_3.

mas discutem, sobretudo, a apropriação teórico-metodológica dos gêneros por professores da Educação Básica. 
No terceiro relato (Figura 3), emerge a prática adotada pelo sujeito-professor em seu trabalho com a leitura na sala de aula, a qual também gira em torno do livro - talvez, menos como um "objeto material" e mais como "objeto fascínio", que encanta e traz prazer. Destacamos que essa repetição do livro como "objeto material" fundamental para leitura não implica, da perspectiva discursiva, a simples reprodução dos dizeres e dos sentidos, mas, sim, a sua retomada em outras condições sócio-histórico-culturais. Inscrito no lugar discursivo de professor, o sujeito faz referência a um continuum de práticas (fazer com que as crianças se apaixonem pelos livros, fazer teatros, apresentar partes da história, fazer a leitura do livro), o qual é enunciado por verbos de ação (fazer e apresentar) que parecem sinalizar o que deve ser feito (os esforços realizados pelo sujeito-professor) para promover o estímulo à leitura (trabalhada de várias maneiras) e ao acesso ao livro/literatura. Esses sentidos têm relação de conflito com a imagem que circula não apenas nas instituições escolares, mas, sobretudo, fora dela, no âmbito social: a de que o aluno, em geral, não gosta de ler porque não é estimulado na escola, pelo professor.

O efeito lúdico que emerge no relato dá a ver um funcionamento discursivo mais "livre", aberto à polissemia (Podemos trabalhar de várias maneiras... o que procuro fazer no primeiro momento é que eles e apaixonem pelo livro... vão contar a história como acharem que devem.), embora os dizeres do sujeito-professor também se inscrevam no fio do discurso pedagógico circular (As crianças adoram e se sentem estimuladas... A história será construída por eles, já fiz e deu super certo.), institucionalizado, "que se garante, garantindo a instituição em que se origina e para a qual tende: a escola" (ORLANDI, 1996, p. 28). Ao ser interpelado pelo discurso pedagógico, o funcionamento discursivo do relato faz vir à tona a construção de uma relação - que contempla a leitura, o livro e a literatura - legitimada pela instituição escola, pelo fazer-saber pedagógico. Nessa perspectiva, emerge, pelo não-dito, que haverá falta de interesse e de gosto da criança pelo livro/literatura se não houver incentivo do professor pelo (bom) trabalho com a leitura, que deve se dar de várias maneiras (teatros, recontos, comparações etc.), como forma de, talvez, garantir o interesse do aluno pela leitura, pelo livro e pela literatura.

\section{CONSIDERAÇÕES FINAIS}

$\mathrm{Na}$ escola, por muitos anos, e ainda hoje, vemos circular discursos que colocam o livro como único acesso à literatura e a leitura como mera decodificação de signos presentes no texto. Nessas concepções, a literatura e a leitura estão submetidas às limitações impostas, social e historicamente, pelos discursos sobre o próprio livro. Há, nesse funcionamento, um conjunto de relações de poder-saber que estão em jogo, principalmente no âmbito escolar, o qual impõe regras e limitações que parecem aprisionar - via documentos oficiais, procedimentos pedagógicos, fala de professores, etc. - o sujeito e o seu saber-fazer, e discursivizar o livro como um "objeto" legitimado. De acordo Larrosa (2004, p. 100),

[...] o discurso pedagógico dá a ler, estabelece o modo de leitura, tutelao e avalia-o ou, dito de outra forma, seleciona o texto, determina a relação legítima com o texto, controla essa relação e ordena hierarquicamente o valor relativo de cada uma das realizações concretas de leitura, distinguindo entre "melhores" e "piores" leituras.

No que concerne ao material analisado, manifestam sentidos - sobre leitura, livro e literatura - que foram construídos ao longo da história, mais precisamente desde a Idade Média, e que são retomados pelos sujeitos-professores como discursos naturalizados. No 
entanto, uma formação discursiva, conforme destaca Pêcheux (1993, p. 314), "não é um espaço estrutural fechado, pois é constitutivamente 'invadida' por elementos que vêm de outro lugar (isto é, de outras FD) que se repetem nela, fornecendo-lhe suas evidências discursivas fundamentais (por exemplo sob a forma de 'pré-contruídos' e de 'discursos transversos')". Desse modo, as diferentes formações discursivas (FD) dos relatos escritos pelos professores da Educação Básica sobre o trabalho com a leitura em sala de aula se relacionam a posições ideológicas que: i) por um lado, determinam o que pode e deve ser dito (PÊCHEUX, 2009), na ordem do discursivo e do institucionalizado, a respeito da leitura, do livro e da literatura; ii) por outro lado, possibilitam o movimento do mesmo que não é sempre o mesmo (BLANCHOT, 2005), dando a ver, na repetição, diferentes efeitos de sentido sobre leitura, livro e literatura.

\section{REFERÊNCIAS}

BLANCHOT, M. O livro por vir. Trad. Bras. São Paulo: Martins Fontes, 2005.

FAILLA, Zoara (Org.). Retratos da leitura no Brasil 4. Rio de Janeiro: Sextante, 2016. Disponível em: http://prolivro.org.br/home/images/2016/RetratosDaLeitura 2016 LIVRO EM PDF FINAL_COM CAPA.pdf. Acesso em 15 abr. 2018.

Retratos da leitura no Brasil 3. Rio de Janeiro: Sextante, 2012. Disponível em: http://www.prolivro.org.br/images/antigo/4095.pdf. Acesso em 15 abr. 2018.

FERREIRA, M.C.L. (Org.). Glossário de termos do discurso. Porto Alegre: UFRGS, 2001.

FOUCAUlT, M. A Arqueologia do Saber. Trad. Bras. 6a. ed. Rio de Janeiro: ForenseUniversitária, 2002.

GALLI, F.C.S.; GARCIA, D.A. Prática leitora e suas discursividades: formações imaginárias e memória discursiva. Raído (online), v. 9, 115-127, 2015. Disponível em: http://ojs.ufgd.edu.br/index.php/Raido/article/view/4661. Acesso em 15 abr. 2018.

GRIGOLETTO, M. Processos de significação na aula de leitura em língua estrangeira. Em: CORACINI, M.J.R.F. O jogo discursivo na aula de leitura: língua materna e língua estrangeira. $2^{\text {a }}$. ed. Campinas: Pontes, 2002. p. 103-111.

LARROSA, J. Linguagem e educação depois de Babel. Belo Horizonte: Autêntica, 2004.

ORLANDI, E.P. Discurso e leitura. 5a . ed. São Paulo: Cortez; Campinas: Ed. da Unicamp, 2000. 1996. A linguagem e seu funcionamento: as formas do discurso. $4^{\mathrm{a}}$. ed. Campinas: Pontes,

PÊCHEUX, M. Semântica e discurso: uma crítica à afirmação do óbvio. $4^{\mathrm{a}}$. ed. Campinas: Ed. da Unicamp, 2009.

Sobre os contextos epistemológicos da análise do discurso. Escritos, $n^{\circ}$ 4. Trad. Bras. Campinas, Nudecri, LABERURB, maio, 7-16, 1999.

. Observações para uma teoria geral das ideologias. Trad. Bras. RUA, n. 1, Campinas,

Unicamp, Labeurb, 63-89, $1995 . \quad$ Disponível em: http://periodicos.sbu.unicamp.br/ojs/index.php/rua/article/view/8638926/6529. Acesso em 15 abr. 2018.

. A Análise de Discurso: três épocas (1983). Em: GADET, F.; HAK, T. (Orgs.). Por uma análise automática do discurso: uma introdução à obra de Michel Pêcheux. $2^{\mathrm{a}}$ ed. Campinas: Editora da Unicamp, 1993. p. 311-318.

SILVA, W.R. et. al. (Orgs.). Gêneros na prática pedagógica: diálogos entre escolas e universidades. Campinas: Pontes Editores, 2016.

ZANDWAIS, Ana. Perspectivas da análise do discurso fundada por Michel Pêcheux na França: uma retomada de percurso. Santa Maria: UFSM, 2009. 
Artigo recebido em: abril de 2018.

Aprovado e revisado em: julho de 2018.

Publicado em: dezembro de 2018.

\section{Para citar este texto:}

GALLI, Fernanda Correa Silveira. Redes discursivas: leitura, livros e literatura. Entremeios [Revista de Estudos do Discurso, ISSN 2179-3514, on-line, www.entremeios.inf.br], Seção Temática [Discurso, arte e literatura - Parte II], Programa de Pós-Graduação em Ciências da Linguagem (PPGCL), Universidade do Vale do Sapucaí (UNIVÁS), Pouso Alegre (MG), vol. 17, p. 185-197, jul. - dez. 2018.

DOI: http://dx.doi.org/10.20337/ISSN2179-3514revistaENTREMEIOSvol17pagina185a197 